\title{
Sample preparation and analytical techniques for determination of polyaromatic hydrocarbons in soils
}

\author{
${ }^{2 *}$ Z. Khan, ${ }^{1,2} \mathrm{~J}$. Troquet and ${ }^{1,2} \mathrm{C}$. Vachelard \\ ${ }^{1}$ Biobasic Environnement ${ }^{\mathrm{TM}}$, Pollution Control through Biotechnology Parc Technologique La Pardieu, France \\ ${ }^{2}$ Laboratoire de Génie Chimique \& Biochimique, Université Blaise Pascal, France
}

Received 11 August 2005;

revised 29 August 2005;

accepted 6 September 2005;

onlined 30 September 2005

\begin{abstract}
Polyaromatic Hydrocarbons (PAHs) have been determined in soil samples for many years. PAHs can arise in the environment from natural sources, oil and petroleum products and combustion processes. Although oil spills influence PAHS concentrations in local areas, the major sources of PAHS are anthropogenic and derived from land based combustion sources. PAHs are globally distributed and the highest concentrations generally occur close to urban centres. Monitoring is essential during the assessment and remediation. It makes further demands on the analytical methods used, since the transformation products are often present in lower concentrations than the parent PAHs and they may be difficult to identify in the complex mixtures found in these samples. It is therefore essential to use powerful analytical tools to fractionate, separate and identify the analyses in the samples. In this paper we review those aspects relating to the analysis and monitoring of PAHs in soils. The aim is to provide an overview of current knowledge, so as to assess the need for future monitoring of PAHs and the present capability for their analysis. Further monitoring of PAHs is justified because of their ubiquity in the environment, their persistence and bioaccumulative properties and their potential for toxicity both to aquatic organisms and human consumers.
\end{abstract}

Key words: hydrocarbons, soils, extraction, analysis

*Corresponding Author, E-mail: zareenkhan123@yahoo.co.in

\section{Introduction}

Environmental analysis often involves analytes in a wide variety of matrices, ranging from air to sewage water to polluted soil samples. Proper sample preparation procedures are necessary to achieve optimum analytical results. The sample preparation and analytical procedures or determinative steps are categorized by the analyte. PAHs are lipophilic compounds that show high affinity for organic matter and their determination in soil always requires powerful extraction techniques to release the strongly sorbed contaminants from the soil material. In this article focus is given on the extraction procedures since these are the most time consuming and labour intensive steps during environmental analysis.

The steps in the analytical chain may be summarized as follows:

- Pretreatment, which is performed to increase the homogeneity of the soil and to increase the extractability of the analytes in the soil.

- Extraction, which is performed to release the contaminants from the solid matrix and quantitatively transfer them to another medium, usually an organic solvent.
- Clean up, which is performed to remove coextracted compounds that could interfere during the subsequent analysis, and to separate different classes of analytes prior to analysis.

- Instrumental analysis, which is performed to separate, identify and quantify the individual analytes in the sample.

\section{Pretreatment}

Before taking a sub sample for analysis, the samples should be sufficiently homogenized. PAHs can be extracted from wet or dried samples. However storage, homogenization and extraction are much easier when the samples are dry. Drying the samples at ambient or elevated temperatures as well as freeze drying may alter the concentrations, eg. by contamination or by loss of compounds through evaporation (Law, et al., 1994). Possible losses and contamination have to be checked. Contamination can be checked by exposing 1-2 g. of C18 bonded silica to drying conditions and analysing it as a sample (Smedes and de Boer, 1998). Contamination during freeze drying is reduced by placing a lid, with a hole about $3 \mathrm{~mm}$. in diameter, on the sample container, 
while evaporation of water is not hindered. Chemical drying of samples can be performed by grinding with sodium sulphate or magnesium sulphate until the sample reaches a sandy consistency. It is essential that at least several hours elapse between grinding and extraction to allow for complete dehydration of the sample. Residual water will decrease extraction efficiency. (USEPA, 1996)

\section{Extraction techniques}

An extraction is usually the first step in analytical procedures applied to the determination of organic compounds in solid matrices. The use of a convenient type of extraction not only influences the accuracy of results but also determines the total analysis time and in this way affects sample throughput and analysis costs. Several efficient extraction techniques have been developed and are commonly used for analyte isolation from solid matrices. The technologies used for the extraction of PAHs from soil samples are more diverse than for water and other liquid samples.

\section{Soil samples}

The techniques vary by the method used to enhance the action of the solvent for the extraction. They range from classic Soxhlet extraction to modern microwave extraction.

\section{Wet soils}

Wet soils can be extracted using a stepwise procedure by mixing with organic solvents or by blending with anhydrous sodium sulphate. Extraction is enhanced by shaking, ultra Turrax mixing or ball mill tumbling. Water miscible solvents such as acetone, methanol or acetonitrile are used in the first step. Acetone/hexane are safer, cheaper and more compatible with subsequent analysis when compared to either toluene or benzene. The extraction efficiency of the first step will be low as there is a considerable amount of water in the liquid phase. For sufficient extraction at least three subsequent extractions are needed. The contact time with the solvent should be sufficient to complete the desorption of the PAHs out of the soil pores. The contact time for the desorption of PAHs from soils may vary up to 24 hrs depending on the soil type. The contact time of the soil with the solvent can be reduced by using microwave heating or a Soxhlet apparatus. When utilising a Soxhlet, the extraction of wet sediments should be conducted in two steps. First a polar solvent such as acetone is used to extract the water from the soil, then the flask is replaced and the extraction continued with a less polar solvent or solvent mixture (acetone/hexane). Thereafter the extracts must be combined. For both batch and Soxhlet extraction, water must be added to the combined extracts and the PAHs must be extracted to a non-polar solvent. Different solvents were used for extraction of PAHs like methylene chloride/acetone (1:1 v/v) (Charles et al., 1998), methylene chloride/ diethyl ether (1:2 v/v) (Amir, et al., 2004; Lega, et al.,1997), ethyl acetate/hexane $(1: 1 \mathrm{v} / \mathrm{v})$, acetone/hexane $(1: 1 \mathrm{v} / \mathrm{v})$ (Juhani et al., 2004), n-butanol (Hans-Holger Liste and Martin Alexander, 2002), Pyridine (Blanco and Guillen 1991, and Disdier et al., 1999), methylene chloride/ methanol (1:1) (Lindhart, et al., 1994), methylene chloride/acetone (1:1) (Guerin,1999) but the preferred solvent system which gives the best recovery is methylene chloride. (Juhani, et al., 2004). When sample results are to be calculated on a dry weight basis, a second portion of the sample should be weighed, dried overnight at $105^{\circ} \mathrm{C}$, cooled and the percentage dry weight calculated.

\section{Dry soils}

Although all the methods mentioned above can also be used for dried soils, Soxhlet extraction is the most frequently applied technique to extract PAHs from dried soils.

\section{Solvents}

The extraction medium (solvent) has a major impact on the extraction results. Medium polar solvents such as dichloromethane or toluene, or mixtures of polar and non-polar solvents are the preferred ones (USEPA, 1978). When using dichloromethane, losses of PAHs have occasionally been observed. Although toluene is not favoured because of its high boiling point it should be chosen as solvent when it is expected that soil samples contain soot particles. Other solvents such as hexane, acetone/hexane $(1: 1 \mathrm{v} / \mathrm{v})$, dichloromethane-acetone $(1: 1 \mathrm{v} / \mathrm{v})$, dichloromethane-ethanol $(1: 1 \mathrm{v} / \mathrm{v})$, nbutanol, (Hatzinger and Alexander, 1995) methanol (Codina et al., 1994), can also be used. Techniques relying on organic solvents are effective in the extraction of organics but the solvents are often hazardous to the environment.

\section{Ultrasonic extraction}

This is the simplest method (Eiceman et al., 1980) which uses mechanical energy in the form of a shearing action which is produced by a low frequency sound wave. A sonication device is used 
which consists of a horn type ultrasonic disruptor equipped with a titanium tip. The disruptor horn tip is positioned just below the surface of the solvent, just above the sample. Extraction can be carried out in duration as short as $3 \mathrm{~min}$. Since it is a fast procedure, it is important that one strictly follow the specific operating conditions. For low concentration samples, the sample needs to be extracted two or more times, each time with the same amount of fresh solvent. Then the extracts from the different extractions are combined. The sample is immersed in an ultrasonic bath with solvent (acetone/methylene chloride $1: 1 \mathrm{v} / \mathrm{v}$ or acetone/hexane $1: 1 \mathrm{v} / \mathrm{v}$ ) and subjected to ultrasonic radiation at $350-450 \mathrm{~W}$ for 2$3 \mathrm{~min}$. The sample is separated from the extract by vacuum filtration or centrifugation. The process is repeated 2-3 times, and the extracts are combined for the analytical step. The solvent receives only minor heating of a few degrees above room temperature and thus cannot provide as thorough extraction of difficult matrices such as aged soil samples.

\section{Soxhlet extraction}

Analytical chemists have used Soxhlet extraction for more than 100 years (Arment, 1999). This method is the classic approach for extracting solid samples (USEPA, 1996; Lopez-Avila et al., 1993) for a spectrum of non and semivolatile organic compounds. It works in a manner analogous to continuous liquid-liquid extraction, except the sample is solid instead of liquid. The sample held in a porous cellulose thimble is extracted continuously with a fresh aliquot of distilled and condensed solvent. Thus, the extraction is performed at temperatures below the solvents boiling point for a period of 16-24 h at 4-6 cycles/h.

\section{Automated Soxhlet extraction}

This technique is an automated version of the classic Soxhlet approach to extracting solid samples, with two modifications. This approach initially immerses the thimble that contains the sample directly into the boiling solvent. Then, the thimble is moved above the solvent to mimic the rinseextraction step of Soxhlet extraction. Finally a concentration step using modern automated equipment reduces the final volume to 1-2 $\mathrm{ml}$. This three-stage approach shortens the extraction step to $2 \mathrm{~h}$, because it provides direct contact between the sample and solvent at the solvents boiling point. Different automated or semi automated extraction instruments are found in the market. As an example
FOSS $^{\mathrm{R}}$ has launched several types of Soxtec systems - automated (Soxtec 2050) and semi automated (Soxtec 2055 \& 2045). The automated Soxtet performs four extraction steps- boiling, rinsing, solvent recovery and cup lifting unattended. The automatic shut down feature permits out of hours operations allowing for high thorough put of up to seven extractions, 42 samples per day. The semi automated Soxtec, a cost effective alternative to the Soxtec 2050, allows for a thorough put of up to 6 extractions, 36 samples per day. This is a cost effective alternative to the Soxtec 2050. Another device by Visco ALPHA ${ }^{\mathrm{R}}$ enables the user to have a 2, 4 or 6 place system in two versions (micro or macro) based on a five step automatic extraction.

The Buchi ${ }^{\mathrm{R}}$ extraction system (B-811) is an automated system which has been used more frequently. It performs extraction according to the original Soxhlet principle the main difference being the method of cycling of the solvent. Four different extraction methods are pos ${ }^{2}$ sible without making any changes to the unit: Soxhlet standard (a cold extraction, as traditional Soxhlet, but with the option of setting both the solvent level in the extractor and the number of extraction cycles), Soxhlet warm (has an extra option of gently heating the solvent whilst it fills the extractor), Hot extraction (the solvent does not cycle over but is retained in the extractor body and heated), Continuous extraction (the sample is continuously flushed with fresh solvent).In addition to the Soxhlet standard and continuous flow extraction, one achieves significant reductions in extraction times especially with the warm and hot extraction modes. There are studies which show a drastic reduction of extraction time from $20 \mathrm{~h}$ to $4 \mathrm{~h}$ when compared with the classic Soxhlet extraction method (Blachnik, 2002). Solvents with boiling points up to $150^{\circ} \mathrm{C}$ can be used because of the high heat output and the optimal heat transfer. The inert design of the extraction system allows contamination free operation with all common solvents. The procedurally integrated evaporation and drying of the extracts shows itself to be especially advantageous by eliminating the use of a rotary evaporator.

\section{Pressurized fluid extraction (Accelerated solvent extraction)}

Pressurized fluid extraction (PFE) is one of the latest technologies to be approved for solid-sample extraction (Richter, 1995, 1996; Ezzell, 1995; Fisher,1997; Kreisselmeier,1997) and has been successfully used in the extraction of PAHs ( Popp et al., 1997; Saim et al., 1997; Saim et al., 1998; 
Kenny and Olesik, 1998). The use of solvent under elevated but sub critical temperatures and pressures was introduced by Dionex in 1995 as Pressurized fluid extraction (Richter, et al., 1995; 1996). The method performs extractions at elevated temperatures $\left(50-200{ }^{\circ} \mathrm{C}\right)$ and pressures (1500-3000 psi). The instrumentation to perform pressurised-fluid extraction, more commonly known by its trade name of accelerated solvent extraction, is semi automated. After loading a sample into the extraction cell and sealing it, the instrument performs the extraction, separation, and collection steps automatically. Samples are processed sequentially in batches of as many as 24 samples. Equipment is available that will perform the extraction of six samples simultaneously (Majors, 1995).Optimisation studies (Zuloaga, et al., 2000) have been conducted on using PFE for analysing PAHS in soils. Different solvents and solvent mixtures were used and best recoveries were calculated. The principle of pressurised fluid extraction is simple. The sample (or a sample mixed with a drying agent) is loaded into a high pressure, high temperature extraction cell which is sealed. The cell is heated to the extraction temperature which often is two to three fold the atmospheric boiling point of the solvent, the extracting solvent is added and held in contact with the sample for 5-10 min; the extract then is flushed from the cell into the collection vessel with a volume equal to $60-75 \%$ of the cell volume; and finally the extract is purged with nitrogen. In pressurised-fluid extraction, the sample is diluted by the volume of extraction solvent and must be concentrated before analysis.

\section{Pressurized hot water extraction (PHWE)}

Pressurized hot water has been extensively used to replace organic solvents in extraction processes. The altered physico-chemical properties of pressurised hot water can be exploited in the extraction of organics from solid samples. Temperatures below the critical temperature of water, but usually above $100^{\circ} \mathrm{C}$ are applied. Pressure has to be high enough to keep the water in liquid state. PHWE has been applied for extraction of many organic compounds including PAHs (Hartonen, 2000; Hawthorne et al., 1994; Yang, 1997; Lagadec et al., 2000; Andersson et al., 2002; Juhani et al., 2004).

\section{Microwave assisted extraction (MAE)}

Microwave energy has been developed recently for the extraction of organic compounds from environmental matrices. (Letellier and Budzinski, 1999; Jingston and Jassie, 1986). The microwave extraction method uses microwave radiation as the source of heating of the solvent-sample mixture (Pare et al., 1994; Eskilsson and Bjorklund, 2000; Majors, 1995). Due to the particular effects of microwaves on matter (namely dipole rotation and ionic conductance), heating with microwaves is instantaneous and occurs in the heart of the sample, leading to very fast extractions. Most of the time the extraction solvent is chosen to absorb microwaves. The results obtained so far have concluded that microwave radiation causes no degradation of the extracted compounds, unless too high a temperature arises in the vessel (Lopez-Avila, et al., 1998). The application of microwave energy to the samples may be performed using two technologies: either closed vessel (under controlled pressure and temperature) or open vessels (at atmospheric pressure) (Camel, 2000; Letellier and Budzinski, 1999). These two technologies are commonly named pressurized MAE (PMAE) or focussed MAE (FMAE). Whereas in open vessels the temperature is limited by the boiling point of the solvent at atmospheric pressure, in closed vessels the temperature may be elevated by simply applying the correct pressure. The system provides significant temperature elevation above the atmospheric boiling point of the solvent, accelerates the extraction process, and yields performance comparable to the standard Soxhlet method. Samples are processed in batches of as many as 14 samples per run. The microwave energy provides very rapid heating of the sample batch to the elevated temperatures, which shortens the extraction time to 10-20 min per batch. Solvent consumption is only $25-50 \mathrm{ml}$ per sample. After the heating cycle is complete, the samples are cooled and the sample is filtered to separate the sample from the extract for the analytical step.

\section{Supercritical fluid extraction (SFE)}

This technique uses supercritical carbon dioxide or carbon dioxide with a modifier to extract polycyclic aromatic hydrocarbons (Hawthorne, et al, 1990, 2000) Hartonen, et al., 2000; Janda, et al., 1993; Chester et al., 1998). Supercritical carbon dioxide or carbon dioxide-organic modifier extracts the sample, which is held in an extraction vessel within a closed system. Supercritical fluids such as carbon dioxide have properties of both liquids and gases, which make them desirable for extraction. When its temperature and pressure are controlled, 
carbon dioxide has the penetrating characteristics of gases and the solvating properties of liquids. This dissolving power can be applied to purify, extract, fractionate, infuse and recrystallize a wide variety of materials. Although pure carbon di oxide is the most common super critical fluid in SFE; its non polar nature means that an organic modifier is often high temperatures and with the correct choice of modifier(s) (Langenfeld et al., 1993, 1994, 1995; Dean, et al., 1995), or ASE at high temperatures (Dean, 1996; Hubert, et al., 2000). Supercritical fluid extraction has also been successfully used to determine the desorption behavior and bioavailability of organic contaminants in soil and sediments

Table 1: Advantages and disadvantages of extraction techniques

\begin{tabular}{|c|c|c|}
\hline Technique & Advantages & Disadvantages \\
\hline Ultrasonic extraction & Short extraction time, simple & Limited extraction efficiency \\
\hline Soxhlet extraction & Simple & $\begin{array}{l}\text { Labor intensive, time and } \\
\text { solvent consumption, analysis } \\
\text { of numerous samples is } \\
\text { limited by the extraction step, } \\
\text { limited extraction efficiency }\end{array}$ \\
\hline Automated Soxhlet extraction & $\begin{array}{l}\text { Time saving, less solvent } \\
\text { consumption, economical, } \\
\text { reproducible, easy operation }\end{array}$ & Instrument cost \\
\hline Pressurized fluid extraction & $\begin{array}{l}\text { Low per extraction cost, less } \\
\text { solvent and time consumption, } \\
\text { simple extraction protocol, } \\
\text { short extraction time, easy } \\
\text { operation. }\end{array}$ & Instrument cost, safety \\
\hline Pressurized hot water extraction & $\begin{array}{l}\text { Nil use of hazardous solvents, } \\
\text { environmental friendly, high } \\
\text { extraction efficiency. }\end{array}$ & Instrument cost, safety \\
\hline Microwave assisted extraction & $\begin{array}{l}\text { Simple instrumentation, } \\
\text { reduced solvent use, short } \\
\text { extraction period }\end{array}$ & $\begin{array}{l}\text { Instrument cost, subjected to } \\
\text { interferences of microwave } \\
\text { energy absorbing materials, } \\
\text { requires filtration after } \\
\text { extraction. }\end{array}$ \\
\hline Supercritical fluid extraction & $\begin{array}{l}\text { Environmental friendly, high } \\
\text { speed of analysis }\end{array}$ & High analytical cost \\
\hline
\end{tabular}

needed for the efficient extraction of compounds with some polarity. The primary operating parameters are the carbon dioxide- modifier flow rates, temperature, pressure and dynamic or static mode of extraction. In the static mode, the extraction cell fills the extraction vessel with the supercritical fluid and holds it in the vessel for a specified period of time. In the dynamic mode, the supercritical fluid passes through the extraction vessel continuously. The depressurised carbon dioxide or carbon dioxide modifier exits the system, and the target compounds are collected in a vessel that contains a suitable solvent or sorbent material.

Modern extraction technologies, such as ultrasonication, microwave extraction, supercritical fluid extraction (SFE), and accelerated solvent extraction (ASE), enhance the kinetics of compound extraction and can improve compound recovery, in comparison with soxhlet extraction techniques (Northcott and Jones, 2000). Improved compound extraction recoveries are obtained by using SFE at
(Bjorklund et al, 2000; Hawthorne and Grabanski, 2000; Weber and Young, 1997). However, the expense of these technologies means they are not readily available to many laboratories that continue to use traditional based solvent extraction methods. Table 1 lists the advantages and disadvantages of all the extraction techniques. To better illustrate the extraction performance of each technique in terms of extraction conditions, time and further treatment required, comparisons are given for some of the applications in Table 2.

\section{Liquid samples \\ Principally, there are two different extraction principles in current use- solid phase extraction (SPE) and liquid liquid extraction (LLE). LLE uses solvents like methylene chloride, hexane, 2-propanol, cyclohexane, acetonitrile to extract the PAHs. Solid phase extraction is a sample treatment technique which passes a liquid sample through a sorbent. Both the analytes to be determined or the interferences}


Table 2: Comparison of technique performances for the extraction of PAHs

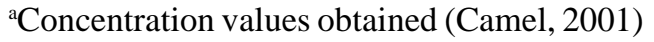

\begin{tabular}{|c|c|c|c|c|c|c|}
\hline Application & Technique & Solvent & Conditions & Time & $\begin{array}{c}\text { Further } \\
\text { treatment after } \\
\text { extraction }\end{array}$ & $\begin{array}{l}\text { Extraction } \\
\text { Results }^{\mathrm{a}}\end{array}$ \\
\hline \multirow[t]{5}{*}{$\begin{array}{c}\text { PAHs/native } \\
\text { contaminated soil }\end{array}$} & Soxhlet & $\mathrm{CH}_{2} \mathrm{Cl}_{2}$ & $\begin{array}{l}\text { 10g. soil+ } 10 \mathrm{~g} . \\
\mathrm{Na}_{2} \mathrm{SO}_{4} ; 150 \mathrm{ml} \text {. } \\
\text { solvent }\end{array}$ & $24 \mathrm{~h}$. & Concentration & $\begin{array}{l}1623 \\
\mathrm{mg} / \mathrm{kg}\end{array}$ \\
\hline & SFE & $\begin{array}{l}\mathrm{CO}_{2}+ \\
20 \% \\
\mathrm{CH}_{3} \mathrm{OH}\end{array}$ & $\begin{array}{l}1 \text { g. soil; } 250 \mathrm{~kg} . \\
\mathrm{cm}^{-2} ; 70^{\circ} \mathrm{C} ; 2 \mathrm{ml} / \mathrm{min} \\
\text { collection: } \mathrm{CH}_{2} \mathrm{Cl}_{2}\end{array}$ & $\begin{array}{l}5 \text { min. static } \\
+30 \text { min. } \\
\text { dynamic }\end{array}$ & Concentration & $\begin{array}{l}1544 \\
\mathrm{mg} / \mathrm{kg}\end{array}$ \\
\hline & PFE & $\begin{array}{l}\mathrm{CH}_{2} \mathrm{Cl}_{2-} \\
\text { acetone, } \\
1: 1\end{array}$ & $\begin{array}{l}\text { 7g. soil; } 100^{\circ} \mathrm{C} \text {; } \\
2000 \text { psi }\end{array}$ & $\begin{array}{l}5 \text { min. } \\
\text { preheating + } \\
5 \text { min. static }\end{array}$ & Concentration & $\begin{array}{l}1537 \\
\mathrm{mg} / \mathrm{kg}\end{array}$ \\
\hline & PMAE & Acetone & $\begin{array}{l}2 \text { g. soil; } 40 \mathrm{ml} \text {. solvent } \\
120^{\circ} \mathrm{C}\end{array}$ & $\begin{array}{l}20 \mathrm{~min}+ \\
\text { cooling }\end{array}$ & $\begin{array}{l}\text { Filtration; } \\
\text { concentration }\end{array}$ & $\begin{array}{l}1578 \\
\mathrm{mg} / \mathrm{kg}\end{array}$ \\
\hline & FMAE & $\mathrm{CH}_{2} \mathrm{Cl}_{2}$ & 2 g. soil; 70 ml. solvent & 20 min. & $\begin{array}{l}\text { Filtration; } \\
\text { concentration }\end{array}$ & $\begin{array}{l}1492 \\
\mathrm{mg} / \mathrm{kg}\end{array}$ \\
\hline \multirow[t]{3}{*}{$\begin{array}{l}\text { PAHs/ } \\
\text { contaminated soil }\end{array}$} & Soxhlet & $\mathrm{CH}_{2} \mathrm{Cl}_{2}$ & $\begin{array}{l}10 \text { g. soil + } 30 \text { g. } \\
\mathrm{Na}_{2} \mathrm{SO}_{4}+100 \mathrm{ml} \text {. } \\
\text { solvent }\end{array}$ & $\begin{array}{l}6 \mathrm{~h} .+ \\
\text { cooling }\end{array}$ & None & $\begin{array}{l}297.4 \\
\mathrm{Mg} / \mathrm{kg}\end{array}$ \\
\hline & SFE & $\begin{array}{l}\mathrm{CO}_{2}+20 \% \\
\mathrm{CH}_{3} \mathrm{OH}\end{array}$ & $\begin{array}{l}1 \text { g. soil; } 250 \mathrm{~kg} \mathrm{~cm}^{-2} \text {; } \\
70^{\circ} \mathrm{C} ; 1 \mathrm{ml} / \mathrm{min} \\
\text { collection: } \mathrm{CH}_{2} \mathrm{Cl}_{2}\end{array}$ & $\begin{array}{l}5 \text { min. static } \\
+60 \text { min. } \\
\text { dynamic }\end{array}$ & None & $\begin{array}{l}458.0 \\
\mathrm{mg} / \mathrm{kg}\end{array}$ \\
\hline & PMAE & Acetone & $\begin{array}{l}2 \text { g. soil; } 40 \mathrm{ml} \text {. } \\
\text { solvent; } 120^{\circ} \mathrm{C}\end{array}$ & $\begin{array}{l}20 \text { min. + } \\
\text { cooling }\end{array}$ & Filtration & $\begin{array}{l}422.9 \\
\mathrm{Mg} / \mathrm{kg}\end{array}$ \\
\hline
\end{tabular}

of the samples are retained on the sorbent by different mechanisms. The analytes are eluted in a small volume of a solvent and so the analytes are concentrated. SPE is increasingly popular because, unlike LLE, it does not require large volumes of organic solvents, analysis time can be decreased significantly and online or automated procedures are easily designed. Another advantage is the wide variety of extraction conditions which may be used to achieve the desired separation and preconcentration. Unfortunately the two procedures do not always yield comparable results as the physical extraction principles are quite different (Sturm et al, 1998; Gomez-Beliachon et al, 1988).

\section{Clean up}

Clean up techniques may be divided into preseparation techniques, which are used to remove the bulk of the co-extracted (biogenic) material, and fractionation techniques, which are used to separate the target analytes in different fractions, and to remove similar anthropogenic compounds. However, for samples that have low organic contents, the preseparation and fractionation steps are often combined into a single fractionation step. The fractionation of PAHS and PAHS transformation products may be performed by adsorption chromatography, using open column chromatography (Chaudhury, 1982; Saponaro et al., 2002; Grifoll et al., 1990), solid phase extraction (SPE) (Wischmann et al., 1996; Moyano and galceran, 1997; Meyer and Steinhart, 1999; Bodzek et al., 1997) or high performance liquid chromatography (Brooks et al., 1998; Fernandez and Bayona, 1992; Allen et al., 1997; Ramdahl, 1983). The HPLC techniques have the greatest resolution and reproducibility, and they may be coupled to sensitive instruments for analyte detection. However, the other techniques are simpler to use, less costly and have higher sample capacity than HPLC, and are therefore widely used in environmental analysis (Hale and Aneiro, 1997). The stationary phases most commonly used for organic contaminants are silica 
gel, alumina and Florisil (Hale and Aneiro, 1997). These are highly active adsorbents, which are often deactivated with water prior to use. This reduces their adsorption capacity and improves their reproducibility. The analytes are eluted from the columns with organic solvents of increasing polarity.

\section{Instrumental analysis}

According to the USEPA both the HPLC and GC/MS methods are considered to be equally valid approaches to analyse PAHs though GC/MS is a widely used method (Disdier et al., 1999).

\section{High performance liquid chromatography}

For adequate HPLC analysis of PAHs, the equipment should meet some minimum requirements. At a minimum, a binary gradient is necessary to achieve proper separation. Using HPLC and measuring concentrations with the peak height, a $50 \%$ valley should be considered as adequate separation. Solvents must be degassed in order to allow proper operation of the high pressure pump. Sample injection should be carried out with an autosampler.

\section{Columns}

The column specifications are:

- stationary phases: e.g., octadecylsilane (RP-18), or special PAHS column material;

- length: 15-25 cm.;

- inner diameter: $4.6 \mathrm{~mm}$ or less;

- particle size: $5 \mu \mathrm{m}$ or less.

Columns with diameters smaller than $4.6 \mathrm{~mm}$ can be chosen in order to reduce the flow of the eluent and thus save solvents, if the dimensions of the detector cell and the tubings are appropriate. When using a smaller diameter column, the amount injected should also be reduced (e.g., $25-50 \mu \mathrm{l}$ for a $4.6 \mathrm{~mm}$ column, 10 to $20 \mu \mathrm{l}$ for a $3 \mathrm{~mm}$ column).

\section{Elution}

At a minimum, a binary gradient is necessary to allow for a proper separation. For elution, e.g., methanol/water or acetonitrile/water can be applied. Acetonitrile allows more rapid flow, but presents a greater health risk than methanol. A typical gradient (1-1.5 ml/min for a $4.6 \mathrm{~mm}$ column) starts at $50 \%$ methanol/water or acetonitrile/water and runs to 100 $\%$ methanol or acetonitrile in 40 minutes, where it remains for 20 minutes and then returns to the initial conditions again for about 5 minutes. Prior to the next injection, the equilibrium time should be about 5-10 minutes (3-5 times the dead volume). $100 \%$ methanol or acetonitrile may not be sufficient to elute all non-target compounds from the column, resulting in peaks that disturb the baseline in the subsequent chromatogram. To avoid this, a further elution step using acetone/methanol $(1 / 1)$ or acetonitrile/acetone (1/1) can be applied. A ternary gradient is then necessary.

In order to obtain reproducible retention times, the equilibrium time after each run should be constant. Therefore, automatic injection is strongly recommended. In addition, a thermostated column compartment $\left(10-30^{\circ} \mathrm{C}\right)$ should be used. Not only retention times but also the resolution between some PAHs can be affected by varying the temperature.

\section{Detection}

For the detection of PAHs, the more sensitive and selective fluorescence detector is preferred to a UV detector. The excitation and emission wavelengths should be programmable to allow the detection of PAHs at their optimum wavelength (Reupert and Brausen, 1994; ISO, 1995). However when PAHs elute close to each other wavelength switching cannot be carried out between these peaks and a wavelength pair appropriate for the respective compounds has to be chosen. The use of two detectors in series or running the analysis twice with different wavelength programmes can minimize the need for such compromises.

As the fluorescence signals of some PAHs can decrease by up to a factor of ten in the presence of oxygen, the eluents must be degassed thoroughly. This can be done either by continuously passing a gentle stream of helium through the eluents or using a commercially available vacuum degasser. In addition, after degassing the eluents, they should not pass PTFE tubings, as this material is permeable to oxygen and allows oxygen to enter the system again. The use of stainless steel or PEEK (polyetheretherketone) tubing is recommended.

\section{Gas chromatography \\ Columns}

Column dimensions for the determination of PAHs should be as follows:

- length: minimum $25 \mathrm{~m}$.;

- inner diameter: maximum $0.25 \mathrm{~mm}$.;

- film thickness: between $0.2 \mu \mathrm{m}$. and $0.4 \mu \mathrm{m}$.;

- stationary phases: a wide range of non-polar or slightly polar stationary phases can be used for 
the separation of PAHs, e.g., a $5 \%$ phenylsubstituted methyl polysiloxane phase.

\section{Carrier gas}

Preferably helium should be used as the carrier gas for GC/MS. When using columns with very small inner diameters, the use of hydrogen is essential. The linear gas velocity should be optimized. Appropriate settings for $0.25 \mathrm{~mm}$. i.d. columns range from $20-40 \mathrm{~cm} / \mathrm{s}$ and for $0.15 \mathrm{~mm}$. i.d. columns from $30-50 \mathrm{~cm} / \mathrm{s}$.

\section{Injection techniques}

An autosampler should be used for injection. The two systems commonly used are splitless and oncolumn injection. Other techniques such as temperature-programmed or pressure-programmed injection may have additional advantages, but should be thoroughly optimized before use. Due to their but increasing errors may result. In addition to a reproducible temperature program, a fixed equilibration time is important for a correct analysis and constant retention times.

\section{Detection}

A frequently used detector for PAHS analysis is a mass spectrometric detector, used in the Selected Ion Monitoring (SIM) mode. Electron impact ionization (El) may be used as the ionization method. The selectivity of a mass spectrometric detector is excellent and the chromatographic noise of a standard is similar to that of a sample. However, major drawbacks are the matrix-dependent response and the convex calibration curves that both often occur and make quantification difficult. As another technique of PAHS identification, the full-scan MS using an ion trap can be mentioned; it operates with

Table 3: High performance liquid chromatography of PAHs

\begin{tabular}{|c|c|c|c|}
\hline \multirow{2}{*}{ Compound } & \multirow{2}{*}{$\begin{array}{l}\text { Retention time } \\
\quad \text { (min.) }\end{array}$} & \multicolumn{2}{|c|}{ Method detection limit ( $\mu \mathrm{g} / \mathrm{l})$} \\
\hline & & UV & Fluorescence \\
\hline Naphthalene & 16.6 & 1.8 & - \\
\hline Acenaphthylene & 18.5 & 2.3 & - \\
\hline Fluorene & 20.5 & 1.8 & - \\
\hline Phenanthrene & 21.2 & 0.21 & 0.64 \\
\hline Anthracene & 22.1 & - & 0.66 \\
\hline Fluoranthrene & 23.4 & - & 0.21 \\
\hline Pyrene & 24.5 & - & 0.27 \\
\hline Benzo(a)Anthracene & 25.4 & - & 0.013 \\
\hline Chrysene & 28.5 & - & 0.15 \\
\hline Benzo(b)fluoranthene & 29.3 & - & 0.018 \\
\hline Benzo(k)flouranthene & 31.6 & - & 0.017 \\
\hline Benzo(a)Pyrene & 32.9 & - & 0.023 \\
\hline Dibenzo(a,h)Anthracene & 33.9 & - & 0.03 \\
\hline Benzo(ghi)perylene & 35.7 & - & 0.076 \\
\hline Indeno(1,2,3-cd)pyrene & 36.3 & - & 0.043 \\
\hline
\end{tabular}

\footnotetext{
HPLC conditions:
}

Reverse phase HC-ODS Sil-X, 5 micron particle size, in a $250 \mathrm{~mm} \times 2.6 \mathrm{~mm}$ I.D. stainless steel column. Isocratic elution for 5 min using acetonitrile:water $(4: 6)(\mathrm{v} / \mathrm{v})$, then linear gradient elution to $100 \%$ acetonitrile over $25 \mathrm{~min}$ at $0.5 \mathrm{ml} / \mathrm{min}$ flow rate. If columns having other internal diameters are used, flow rate should be adjusted to maintain a linear velocity of $2 \mathrm{~mm} / \mathrm{sec}$.

high boiling points, for PAHs on-column injection is recommended.

\section{Temperature programming}

The temperature program must be optimized for a sufficient separation of the PAHS compounds. The preferred operating conditions with the retention times of some of the PAHs are given in Table 2 (USEPA, 1978).

For GC/MS analysis peak area is generally used, and a $10 \%$ valley would represent a good separation. Less resolved peaks may also be quantified (for instance, by dropping perpendiculars to the baseline), the same sensitivity as SIM but is a much more powerful analytical tool. The use of a flame ionization detector (FID) is also possible, but since the selectivity of the FID is low, it is not recommended.

\section{Identification}

The individual PAHs are identified by comparing the retention time of the substance in a sample with that of the respective compound in a standard solution analysed under the same conditions (Tables 2 and 3). In case of doubt, it is recommended to 
confirm the results by using a different wavelength for UV-absorption or a different combination of wavelengths for fluorescence detection. Using a GC/ MS system, the molecular mass or characteristic mass fragments are a suitable way to prove the identification of the PAHs compound by using a library database (NIST library search). Using GC/ MS on a modern instrument, the retention times should be reproducible to within \pm 0.05 minutes, and additionally there are deuterated analogues of many of the parent compounds present for comparative purposes. For HPLC, reproducibility of retention times may be less good, but should certainly be within \pm 1 minute. to be suitable for GC/MS as well as for HPLC analysis. The use of several deuterated PAHs spanning the entire molecular weight range as internal standards is encouraged. For example, for GC/MS it is recommended to add four internal standards representing different ring-sizes of PAHs. The following compounds can be used (Wise et al, 1995):

- for HPLC analysis: phenanthrene-d10, fluoranthene-d10, perylene-d12, 6-methylchrysene;

- for GC/MS analysis: naphthalene-d8,

\begin{tabular}{|lccc|}
\hline \multicolumn{1}{c}{ Compound } & $\begin{array}{c}\text { Retention time } \\
\text { (min.) }\end{array}$ & \multicolumn{2}{c|}{ Quantitative ions (m/z) } \\
\hline Naphthalene & 9.82 & 128 & $1^{\circ}$ ions \\
Acenaphthylene & 15.13 & 154 & 129,127 \\
Fluorene & 16.70 & 166 & 153,152 \\
Phenanthrene & 19.62 & 178 & 165,167 \\
Anthracene & 19.77 & 178 & 176,176 \\
Fluoranthrene & 23.33 & 202 & 101,203 \\
Pyrene & 24.02 & 202 & 200,203 \\
Benzo(a)Anthracene & 31.45 & 252 & 253,125 \\
Chrysene & 27.83 & 228 & 229,226 \\
Benzo(b)fluoranthene & 27.97 & 228 & 226,229 \\
Benzo(k)flouranthene & 31.55 & 252 & 253,125 \\
Benzo(a)Pyrene & 32.80 & 252 & 253,125 \\
Dibenzo(a,h)Anthracene & 38.82 & 278 & 139,279 \\
Benzo(ghi)perylene & 41.43 & 276 & 138,277 \\
\hline
\end{tabular}

GC-MS conditions:

Mass range: $35-500 \mathrm{amu}$, Scan time: $1 \mathrm{sec} / \mathrm{sec}$, Initial temperature: $40^{\circ} \mathrm{C}$ (hold for 4 minutes), Final temperature $-40-270^{\circ} \mathrm{C}$ at $10^{\circ} \mathrm{C} / \mathrm{min}$, Injector temperature: $250-300^{\circ} \mathrm{C}$ ), Tansfer line temperature : $250-300^{\circ} \mathrm{C}$, Carrier gas : Hydrogen $(50 \mathrm{~cm} / \mathrm{sec}) /$ Helium $(30 \mathrm{~cm} / \mathrm{sec})$, Injection volume : $1-2 \mu \mathrm{L}$.

\section{Quantification}

PAHS determinations should preferably be carried out using calibration solutions prepared from certified, crystalline PAHs. However, the laboratory should have the appropriate equipment and the expertise to handle these hazardous crystalline substances. Alternatively, certified PAHS solutions, preferably from two different suppliers, can be used. Two independent stock solutions should always be prepared simultaneously to allow a cross-check to be made. Calibration solutions should be stored in ampoules in a cool, dark place. Weight loss during storage should be recorded for all standards.

Internal standards should be added to all standards and samples either in a fixed volume or by weight. The internal standards should preferably be non-natural PAHs which are not found in sediment samples and do not co-elute with the target PAHs. Several perdeuterated PAHs have proved phenanthrene-d10, chrysene-dl2, perylene-dl2. A multilevel calibration with at least five concentration levels is recommended. For UV and fluorescence detection, the linear range is large. The calibration curve should be linear and should cover the working range. Since the mass spectrometric detector often has no linear response curve, the use of stable, deuterated isotopes is a prerequisite. Furthermore, the response of PAHs in standard solutions is often much lower than in sample extracts. Only a combination of different techniques, e.g., the use of internal standard and standard addition, might give reliable quantitative results.

The calibration curve can be checked by recalculating the standards as if they were samples and comparing these results with the nominal values. Deviations from the nominal values should not exceed $5 \%$. 
When chromatograms are processed using automated integrators, the baseline is not always set correctly, and always needs visual inspection. Because in HPLC analysis the separation of the peaks is often incomplete, the use of peak heights is recommended for quantification. Using GC techniques, either peak heights or peak areas can be used.

Prior to running a series of samples and standards, the GC or HPLC systems should be equilibrated by injecting at least one sample extract, the data of which should be ignored. In addition, standards used for multilevel calibration should be regularly distributed over the sample series so matrix-and nonmatrix-containing injections alternate. A sample series should include:

- a procedural blank;

- a laboratory reference material;

- at least five standards;

- one standard that has been treated similarly to the samples (recovery determination).

The limit of determination should depend on the purpose of the investigation. A limit of $2 \mathrm{ng} / \mathrm{g}$ (dry weight) or better should be attained for single compounds.

\section{Conclusion}

Choosing the right technique for the right application requires a consideration of the features of the matrix and of the correct analytes. In terms of extraction efficiencies once correctly optimized for a given solute matrix couple all techniques are comparable. For the same class of compounds different results may be obtained when several matrices have to be extracted. The matrix effects due to strong adsorption of the solutes onto the matrix are particularly crucial for environmental matrices.

\section{Reference}

Allen J. O., Dookeran N. M., Taghzadeh K., Lafleur A. L., Smith K. A. and Sarofim A. F., (1997). Measurement of owygentated polycyclic aromatic hydrocarbons associated with a size segregated urban aerosol. Environ Sci Technol 31, 2064-2070.

Amir S., Hafidi M., Merlina G., Hamdi H. and Revel J. C., (2004). Fate of polycyclic aromatic hydrocarbons during composting of lagooning sewage sludge. Chemosphere (in press).

Andersson T., Hartonen K., Hyotylainen T. and Riekkola M. L., (2002). Pressurised hot water extraction and thermal desorption of polycyclic aromatic hydrocarbons from sediment with use of a novel extraction vessel. Anal chim Acta 446, 93-100.

Anonymous, (1978). Interim methods for the sampling and analysis of priority pollutants in sediments and fish tissue, EPA SW 846. Environmental Monitoring Support Laboratory (EPA-EMSL), Cincinnatti, OH, U.S. Environmental Protection Agency.

Anonymous, (1991), Draft International standard/ Soil quality- determination of polynuclear aromatic hydrocarbons-methods using high performance liquid chromatography. International organisation for Standardisation, Paris.Blanco J, Buillen MD, Energy and Fuels, 5, 88-192, ISO.1995 ISO/DIS 13877.

Anonymous., (1996). Method 3540C, Soxhlet Extraction, Test methods for evaluating solid waste, EPA, Washington DC, U.S. Environmental Protection Agency.

Arment S., (1999). Current trends and developments in sample preparation, LCGC, 17(6), 8-13.

Bjorklund E., Nilsson B. T., Bowadt S., Pilorz K., Mathiasson L. and Hawthorne S. B., (2000). Introducing selective supercritical fluid extraction as a new tool for determining sorption/desorption behaviour and bioavailability of persistent organic pollutants in sediment. J. Biochem. Biophys. Methods 43, 295-311.

Blachnik C., (2002). Comparison of Buchi extraction system B-811 with classic Soxhlet extraction. Buchi information bulletin.

Bodzek D., Janoszka B., Dobosz C., Warzecha L. and Bodzek M., (1997). Determination of polycyclic aromatic compounds and heavy metals in sludges from biological sewage treatment plants. J.Chromatogr A 774:177-192.

Brooks L. R., Hughes T. J., Claxton L. D., Austern B., Brenner R. and Kremer F., (1998). Bioassay-directed fractionation and chemical identification of mutagens in bioremediated soils. Environ Health Perspect 106,1435-1440.

Camel V., (2000). Trends Anal. Chem, 19, 229.

Camel V., (2001). Recent extraction techniques for solid matrices-supercritical fluid extraction, pressurized fluid extraction and microwave assisted extraction: their potential and pitfalls. Analyst, 126, 1182-1193.

Charles O. N., Gauthreaux K., Sneddon J. and Beck J. N., (1998). Determination of semivolatile organic compounds by gas chromatography-mass spectrometry in reclaimed marsh sediments in southwest Louisiana. Microchem. J., 60, 167-174.

Chester T. L., Pinkston J. D. and Raynie D. E., (1998). Anal. Chem, 70, 301. 
Choudhury D. R., Characterization of polycyclic ketones and quinones in diesel emission particulates by gas chromatography mass-spectrometry, Environ Sci Technol, 16, 102-106.

Codina G.,Vaquero M. T., Comellas L. and Broto-Puig F., (1994). Comparison of various extraction and clean-up methods for the determination of polycyclic aromatic hydrocarbons in sewage sludge-amended soils. J. Chromatogr., 673:21-29.

Dean J. R., Barnabas I. J. and Fowlis I., (1995). Extraction of polycyclic aromatic hydrocarbons from highly contaminated soil: A comparison between soxhlet, microwave and supercritical fluid extraction techniques. Anal Proc., 32, 305-308.

Dean J. R., (1996). Accelerated solvent extraction of polycyclic aromatic hydrocarbons from contaminated soil. Anal, Commun., 33, 191-192.

Disdier B., Arfi C., Pastor J., Pauli A. M. and Portugal H., (1999). Analysis by GC-MS of monocyclic and polycyclic aromatic hydrocarbons in thermolysed waste products. Analusis, 27, 235-241.

Eiceman G. A., Viu A. C. and Karasek F.W., (1980). Analy. Chem., 52,1492.

Eskilsson C. S. and Bjorklund E. J., (2000). Chromatogr. 902, 227.

Fernandez P. and Bayona J. M., (1992). Use of off-line gel permeation chromatography normal phase liquid chromatography for the determination of polycyclic aromatic compounds in environmental samples and standard reference materials (air particulate matter and marine sediment). J. Chromatogr. 625, 141-149.

Fisher J. A., Scarlett M. J. and Stott A. D., (1997). Environ. Sci. Technol., 31, 1120.

Gomez-Belinchon, J. I., Grimalt J. O. and Albeiges J., (1988). Environ. Sci. Technol., 22,677-685.

Grifoll M., Solanas A. M. and Bayona J. M., (1990). Characterisation of Genotoxic components in sediments by mass -spectrometric techniques combined with salmonella microsome test. Arch. Environ. Contamin. Toxic., 19, 175-184.

Guerin T. F., (1999). The extraction of aged polylcylic aromatic hydrocarbon(PAHS) residues from a clay soil using sonication and a Soxhlet procedure :A comparitive study, J.Environ.Monit., 1,63-67.

Hale R. C. and Aneiro K. M., (1997). Determination of coal tar and creosote constituents in the aquatic environment. J. Chromatogr., 774, 79-95.
Hans-Holger L., Alexander M., (2002). Butanol extraction to predict bioavailability of PAHs in soil. Chemosphere., 46(7), 1011-1017.

Hartonen K., Bowadt S., Hawthorene S. B. and Riekkola M. L., (1997). Supercritical fluid extraction with solidphase trapping of chlorinated and brominated pollutants from sediment samples. J. Chromatogr. 774, 229-242.

Hartonen K., Meissner G., Kesala T. and Riekkola M. L., (2000). Pressurized hot water extraction (PHWE) of n-alkanes and PAHs (PAHs): Comparison for PAHs with supercritical fluid extraction. J Microcolumn, 412-.

Hatzinger P. B. and Alexander M., (1995). Effect of aging of chemicals in soil on their biodegradability and extractability. Environ. Sci. Technol., 29, 537-545.

Hawthorne S. B. and C. B. Grabanski., (2000). Correlating selective supercritical fluid extraction with bioremediation behavior of PAHs in a field treatment plot. Environ. Sci. Technol., 34, 4103-4110.

Hawthorne S. B., Grabanski C. B., Martin E. and Miller D. J., (2000). Comparisons of Soxhlet extraction, pressurized liquid extraction, supercritical water extraction for environmental solids: recovery, selectivity and effects on sapmle matrix. J. Chromatogr. 892, 421-433.

Hubert A., Wenzel K. D., Manz M., Weissflog L., Engewald W., Schuurmann G., (2000). High extraction efficiency for POPs in real contaminated soil samples using accelerated solvent extraction. Anal. Chem., 72, 12941300 .

Janda V., Bartle K. D., Clifford A. A., (1993). J. Chromatogr., 642, 283.

Juhani K., Kettunen J., Hartonen K., and Marja-Lissa R., (2004). Pressurised hot water extraction of nAlkanes and PAHs in soil and sediment from the oil shale industry district in Estonia, J. Soils Sediments, $1-8$.

Kenny D. V., Olesik S. V., (1998). J. Chromatogr. Sci., 36, 59 .

Kreisselmeier A. and Durbeck H. W., (1997). J. Chromatogr., 775, 187.

Lagadec A. J. M., Miller D. J., Lilke Q. A. V. and Hawthorne S. B., (2000). Pilot scale subcritical water remediation of polycyclic aromatic hydrocarbon and pesticide contaminated soil. Environ. Sci. Technol., 34, 1542-1548.

Langenfeld J. J., Hawthorne, S. B., Miller, D. J., Pawliszyn, J., (1993). Effects of temperature and pressure on supercritical fluid extraction efficiencies 
of polycyclic aromatic hydrocarbons and polychlorinated biphenyls. Anal. Chem., 65, 338-344.

Law R. J., Klungsøyr J., Roose P. and de Waal W., (1994). QUASIMEME Workshop III: Summary of seminar and poster sessions. Marine Pollution Bulletin, 29, 217221.

Letellier M. and Budzinski H., (1999). Microwave assisted extraction of organic compounds, Analusis, 27, 259-271.

Lindhardt B., Holst H. and Christensen T. H., (1997). Int. J. Environ. Anal. Chem., 69, 2171.

Lopez-Avila V., Benedicto J.and Bauer K. M., (1998). J. AOAC. Int., 81, 1224.

Lopez-Avila V., Young R. and Beckert W. F., (1998). J.AOAC Int., 81, 462.

Majors R. E., (1995). Current trends and developments in sample preparation, LC-GC Int., 8, 128.

Meyer S., Cartellieri S. and Steinhart H., (1999). Simultaneous determination of PAHs, hetero$\mathrm{PAHs}(\mathrm{N}, \mathrm{S}, \mathrm{O})$ and their degradation products in creosote-contaminated soils. Method development, validation and application to hazardous waste sites. Anal.Chem., 71, 4023-4029.

Moyano E. and Galceran M. T., (1997). Determination of oxy-, nitro- and hydroxypolycyclic aromatic hydrocarbons in atmospheric aerosol samples. Quim. Anal. (Barcelona), 16, 159-164.

Northcott G. L. and Jones K. C., (2000). A review of experimental methodologies and analytical techniques for the characterisation of organic compound bound residues in soil and sediment. Environ. Pollut., 108, 19-43.

Pare J. R. J., Belanger J. M. R. and Stafford S. S., (1994). Trends Anal. Chem., 13, 176.

Popp P., Keil P., Moder M., Paschke A. and Thuss U., (1997). J.Chromatogr., 774, 203.

Ramdahl T., (1983). Polycyclic aromatic ketones in environmental samples. Environ. Sci. Technol., 17, 666-670.

Reupert R. and Brausen G., (1994). Determination of polycyclic aromatic hydrocarbons in water, sediments, sludges and soils by high performance liquid chromatography. Acta. Hydrochimica. et. Hydrobiolica., 22,202-215.

Richter B. E., Jones B. A., Ezzel J. L., Porter A. N. and Pohl Ch., (1996). Anal. Chem., 68, 1033.
Saim N., Dean J. R., Abdullah M. P. and Zakaria Z., (1998). Anal. Chem., 70,420.

Saponaro S., Bonomo L., Petruzzelli G., Romele L. and Barbafieri M., (2002). Polycyclic aromatic hydrocarbons (PAHs) slurry phase bioremediation of a manufacturing gas plant (MGP) site aged soil. Water Air Soil Pollut., 135, 219-236.

Smedes F. and de Boer J., (1998). Chlorobiphenyls in marine sediments: Guidelines for determination. ICES, Techni. Marine Environ. Sci., 21, 24.

Sturm B., Knauth H. D., Tehobald N., Wiinsch G., (1988). Hydrophobic organic micropollutants in samples of coastal waters: efficiency of solid phase extraction in the presence of humic substances. Fresenius J. Anal. Chem., 361, 803-810.

Weber W. J. and Young T. M., (1997). A distributed reactivity model for sorption by soils and sediments. 6. Mechanistic implications of desorption under supercritical fluid conditions. Environ. Sci. Technol., 31, 1686-1691.

Wischmann H., Steinhart H., Hupe K., Montresori G. and Stegmann R., (1996). Degradation of selected PAHs in soil/compost and identification of intermediates, Int. J. Environ. Anal. Chem., 64, 247-255.

Wise S. A., Schantz M. M., Benner B. A., Hays M. J. and Schiller, S. B., (1995). Certification of polycyclic qromatic hydrocarbons in a marine sediment standard reference material. Anal. Chem., 67,1171-1178.

Yang Y., Hawthorne S. B., Yang Y. and Miller D. J., (1997). Class-selective extraction of polar, moderately polar, and nonpolar organics from hydrocarbon wastes using subcritical water, Environ. Sci. Technol., 31,430437.

Zuloaga O., Fitzpatrick L. J., Etxebarria N. and Dean J. $R .$, (2000). Influence of solvent and soil type on the pressurised fluid extracts of PAHs. 2(6),634-638. 